\title{
Factors affecting support services in small and medium enterprises: Evidence from Vietnam small and medium information technology enterprises
}

\author{
Vu Ngoc Xuan ${ }^{a^{*}}$, Nguyen Thi Phuong Thu and Ngo Tuan Anh ${ }^{a}$
}

${ }^{a}$ Center for Analysis Forecasting and Sustainable Development, National Economics University, Vietnam

\begin{tabular}{l}
\hline C H R O N I C L E \\
\hline Article history: \\
Received: July 182019 \\
Received in revised format: July \\
282019 \\
Accepted: August 28, 2019 \\
Available online: \\
September 1, 2019 \\
\hline Keywords: \\
Information technology (IT) \\
Business support services (BSS) \\
Information technology enter- \\
prises (ITE) \\
Service supplier (SS)
\end{tabular}

\section{A B S T R A C T}

\begin{abstract}
To meet the needs of innovation, to improve the competitiveness of information technology based on the professional abilities and resources, internal business is not enough, but there is a need to seek external support through business support services such as market search support, trade promotion, legal advice, human resource training, support supply and technology transfer support. There are several services to support businesses and to increase efficiency when they are developed in both quantity and scale of service provision and quality, as well as service structure. So how do we analyze the factors that affect information technology support services in Vietnam? Answering this question helps to suggest solutions and policies to promote the development of the business support service sector and contributes to the rapid development of information technology enterprises in Vietnam. This paper uses information from a survey data of 315 Vietnamese information technology (IT) of small and medium sized enterprises and 460 support service providers in 2018. Data are processed through STATA software version 14.0, and SPSS 20.0 software. The results indicate the Vietnamese business units need to improve to develop the information technology service market, significantly.
\end{abstract}

\section{Introduction}

\subsection{Objectives and research questions}

The primary objective of this paper is to propose directions, solutions and recommendations to develop services to support small and medium-sized information technology enterprises in Vietnam and contributing to the development of businesses. Information technology (IT) industry has become the key businesses for Vietnam's economic development. Specific research objectives are as follows. First, we present a systematic argument for developing IT support services; secondly, we analyze the current circumstances of developing IT support services in Vietnam. Finally, we propose solutions and recommendations to develop services to support IT enterprises in Vietnam. To answer the management question, the research process focuses on answers for research questions: (1) What type of information in Vietnam are used for developing enterprise support services of technology enterprises. (2) What are the key factors affecting the development of business support services of information technology enterprises in Vietnam?

\subsection{Object and scope of research}

Objects: factors affecting service support for small and medium-sized information technology enterprises in Vietnam.

Limit research content: Ministry of Information and Communication divides information technology enterprises into three categories: hardware enterprises, software enterprises and digital content enterprises. However, hardware enterprises have the same characteristics as an industrial enterprise and their characteristics are different from the other two types of information

* Corresponding author.

E-mail address: xuanvn@neu.edu.vn (V. N. Xuan) 
technology enterprises, namely software enterprises and domestic enterprises capacity. In addition, software enterprises and digital content enterprises have specific characteristics of the information technology industry, in which many software enterprises operate in both digital content and vice versa (Bell, 1997; Ensign, 2001; El Wassal, 2013). Therefore, the article focuses on research services to support software businesses and digital content enterprises.

\section{Literature Review}

Edgcomb and Thetford (2010) developed the scale of enterprise support services, which is the achievement of a service goal. When a large number of customers are simultaneously developing scale there is an increasing market penetration rates, which helps gain economic efficiency to provide services which could lead to the sustainability of organizations and suppliers service and bring a profound social impact (Berry et al., 2006; Armenakis \& Bedeian, 1999; Kim et al., 2010). Research shows that the development of the number of service provider may achieve significant improvement in customer satisfaction (Boter \& Lundström, 2005; Govindaraju \& Lukman, 2012). The study has given some criteria to measure the development in scale such as the number of enterprises using services supporting enterprises, increasing the rate of market entry, the increase in customer retention rate, etc. Research also shows that the increase in customer retention rate is an important indicator for developing service scale and it helps increase in revenue and support businesses. Customer retention rates depend on whether the support service provides value for businesses to use; those values can be both tangible and intangible. The study of Kox et al. (2007) analyzed the causes of the strong development of business support services (BSS) and its impact on the European general economy. They also pointed out the factors affecting BSS and demonstrated the great role of BSS in the specialization of services, product innovation and technological innovation such as information technology.

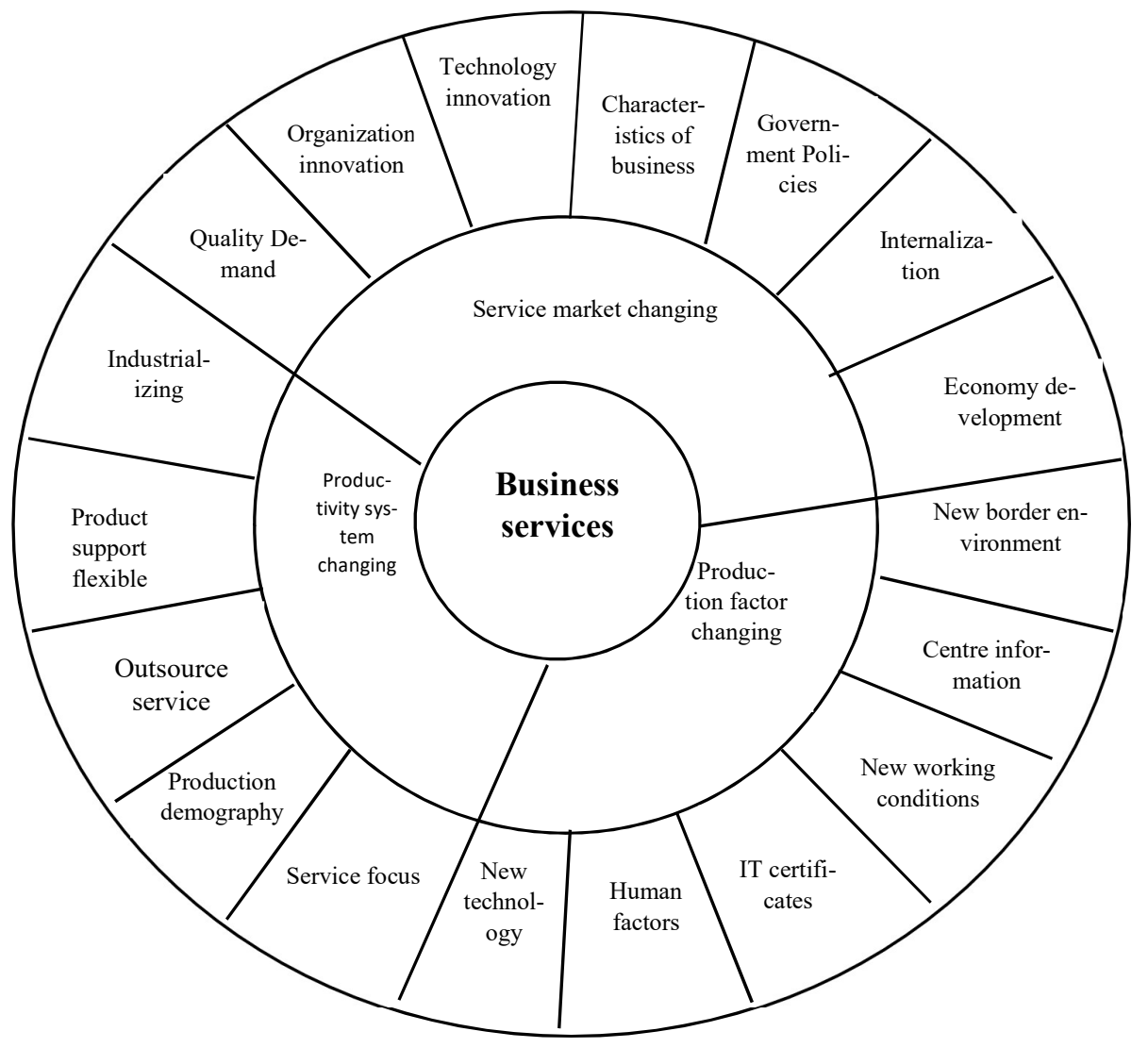

Fig. 1. Factors affecting business service development

Source: Kox et al. (2007)

Factors affecting business services are divided into three groups related to 3 contents: changes in system productivity, changes in production factors and changes in service markets. The three aspects in the middle circle are related to each other and with 18 elements in the outer circle. These factors include broad-based socio-economic changes, which influence on the development of services such as new service consumers, demand productivity and necessary productivity, income growth, technology change, outsourcing, skills improvement, market integration and globalization, different impacts on structural change and the role of public services and private services. Research shows an increase on productivity helps European business services systems, significantly. The average professional qualification of employees in the business service sector is higher than other 
industries. At the same time, the business service sector always shows strong cyclical fluctuations quite similar to manufacturing. The growth phase and the business cycle in production may reflect a strong link between the need for intermediaries and the increasing globalization of some service markets, the period of low-cycle production dynamic, business service industry, etc. However, the study only evaluates the business service system rather than studying the service system to meet the needs of a specific type of enterprise. In addition, 18 factors affecting this business service are difficult to measure in practice.

A study by Romijn et al. (2003) indicates that business support services can increase the impact and the efficiency by placing businesses to use support services at a central, receiving location plays an important role of support service businesses who co-develop new generation services. This study suggests one of the measures to develop business support services by having a combination of support service providers and service-using businesses, derived from the needs of business users used to create new types of services suitable for each business object operating in specific sectors and fields. However, the research did not show how the support services were currently provided, which support services are suitable for the needs of the business and which support services need to be improved, removed or replaced to fit the needs of the business, but only provided ways to develop new services. The study by Brijlal (2008) examined how small and micro enterprises use support services and identified types of products and support services that best suit their needs. The study divided businesses into four categories according to the developmental stages of the business: Survivalist, Stable, Development Trends and Global Competitiveness. He found the types of support services suitable for each type of enterprise in each development stage.

Studies in this approach are mainly about the surface of the service, the outward manifestations of the service, but not the nature of the service, the structure and the content of the service.

\subsection{Studies on the effectiveness of enterprise support services}

The study of Miehlbradt (2002) and Miehlbradt and McVay (2003) evaluated the market for business development services in countries: Thailand, Cambodia, Ghana and Indonesia (2000), GTZ in Nepal (1999), Swiss contact in Bangladesh (2000). The study concluded that real service development in the current enterprise support service model needs to shorten the "gap" of the current approach towards offering services and focusing on business. Short-term numbers and profits generated through short-term market transactions. The point suggests a new approach, built on the recognition that service development needs to be through continuous and interactive business support services innovation among the parties in the market. In this alternative model, enterprises using support services are not only considered as purchasers of services but they are also co-developers and co-producers of new services in partnership with suppliers. Businesses using support services that decide on services will be provided by paying support providers; this approach is called demand-driven enterprise support bridge. Service providers support businesses to develop new products and services, find new markets, set standards, or influence government policies. New services need quickly prove their values on the market through the willingness to pay for these new services by some small businesses. Services that do not pass this test for a short time after birth will automatically disappear. The study by Sheikh et al. (2002) was conducted by the Austrian Small Business Research Institute under the auspices of the European Union (EU). The study is similar in many countries such as Germany, Italy, Luxembourg, Denmark, Netherlands, Finland, Norway, France, Portugal, Belgium, Spain, Greece, Sweden and the United Kingdom. The results of the study provided a comprehensive overview of the description and analysis of existing national and local support services, or systems that integrate those services, to meet the needs of micro, small and private enterprises. It analyzed the needs of small and micro enterprises in Europe, thus providing comprehensive elements to improve the provision of support services for micro, small and one-owner enterprises private in these countries. In the study, there is also limited support for business services that provide information, advice, training, or include business services provided on a non-financial basis and derived from policy public. Thus, the study considers the support service for enterprises but does not consider much the ability to collect fees from business support services.

The study accomplished by Mole (2002) and Mole K. et al. (2009) focused on assessing the effectiveness of Business Link (BL) networks in the UK. BL is a small support service network established in 1992 with many changes over time. The study aimed to answer two questions: what type of business receives support services from the business network? What benefits do businesses receive from those supports? Previous study of Roper and Hart (2005) shows a positive employment growth effects when businesses receive support from BL. In this study, Mole et al. (2009) evaluated and compared the effectiveness of the two types of services that support enterprises, namely "supportive support services", which are regular and ongoing support. The research results show that there was no relationship between the growths of revenue of enterprises with "support services are not enhanced" but the growth of revenue of enterprises using support services had positive relationship with "strengthening support services". It can see that enterprises often use support services and have long-term relationships with support service providers will contribute to improving business performance of enterprises. Research on the impact of support services on target customers are small, medium and micro enterprises by Eiligmann (2005) investigated the Economic Sector Development and Reform Project Private in Eschborn, Germany. Stemming from practice, the provision of support services in the way of full funding and free supply often leads to ineffective and unsustainable support services when donors withdraw. Many support services projects have failed to reduce subsidies, as poor businesses are not willing to pay more for using support services when subsidies are reduced. Therefore, the study explained that from the beginning when providing, support services should be marketable. Although the customers who use the project's support services are mainly small and small enterprises (considered poor enterprises), the project still aims to promote the commercial market for the epidemic support case. About enterprise support services: Many supportive service researchers including Wren and Storey (2002), Council of European Community Donors (European Commission, 2002) for that support services should be non-financial services and towards 
improving market skills and knowledge. Agreeing with the above point of view, the article limits the research support services in the article are non-financial support services. The non-financial support services studied in the article include the basic support services system, general support services and some intensive support services that are currently being accessed by information technology enterprises in Vietnam. The support services studied in the article excluded financial support services such as capital support, tax incentives.

Limited research space: in the research article, support users are information technology enterprises in Vietnam, in which the survey data are typically concentrated in 3 big cities: Ho Chi Minh City, Hanoi City and Da Nang City. There are over 50\% of information technology enterprises operating in Ho Chi Minh City; 40\% of information technology enterprises operating in Hanoi, the rest less than $10 \%$ operate in other provinces and cities. The business support service provider is all business support service providers in Vietnam, focusing on support service providers in three major cities, Hanoi and Ho Chi Minh City, Da nang. because of the high density of information technology enterprises operating in these three cities.

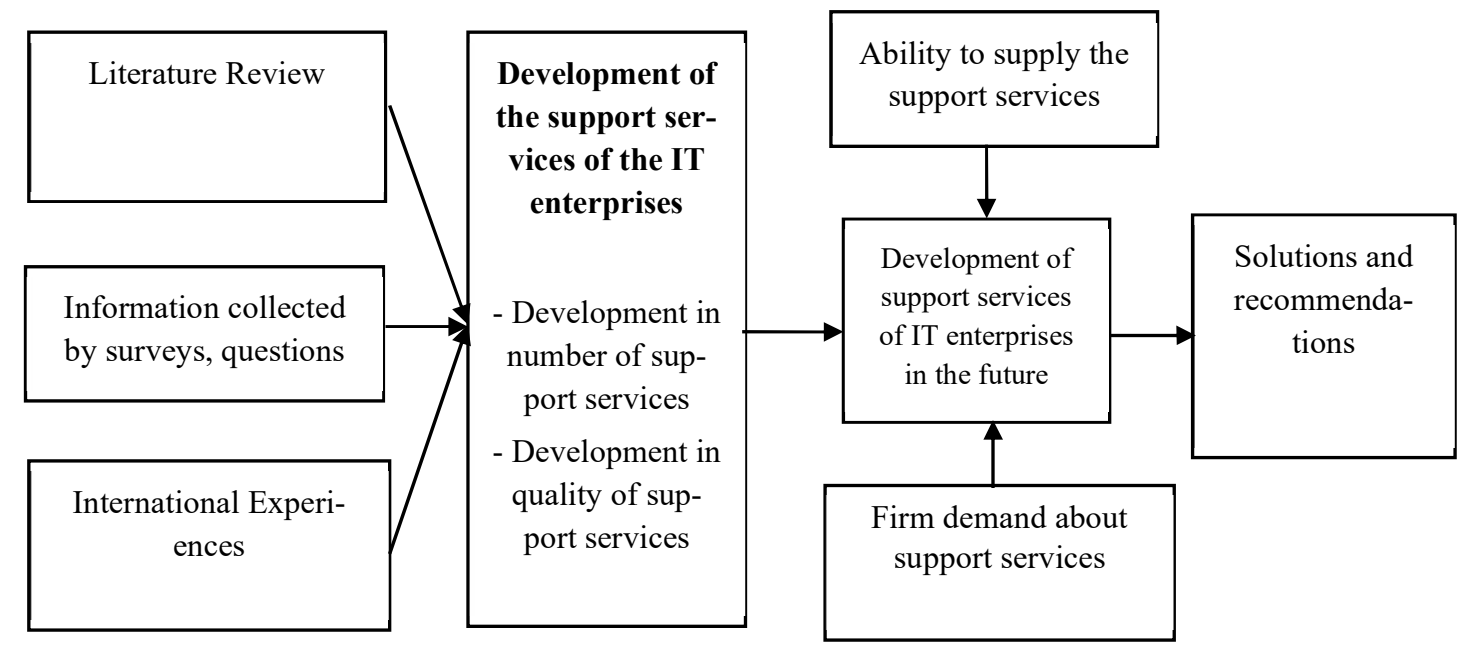

Fig. 2. Research process to develop services to support information technology enterprises in Vietnam

(Source: compiled by authors)

From the point of view of developing enterprise support services, the authors have applied developing services to support a specific business object, such as information technology enterprises in Vietnam, as shown in Fig. 3.

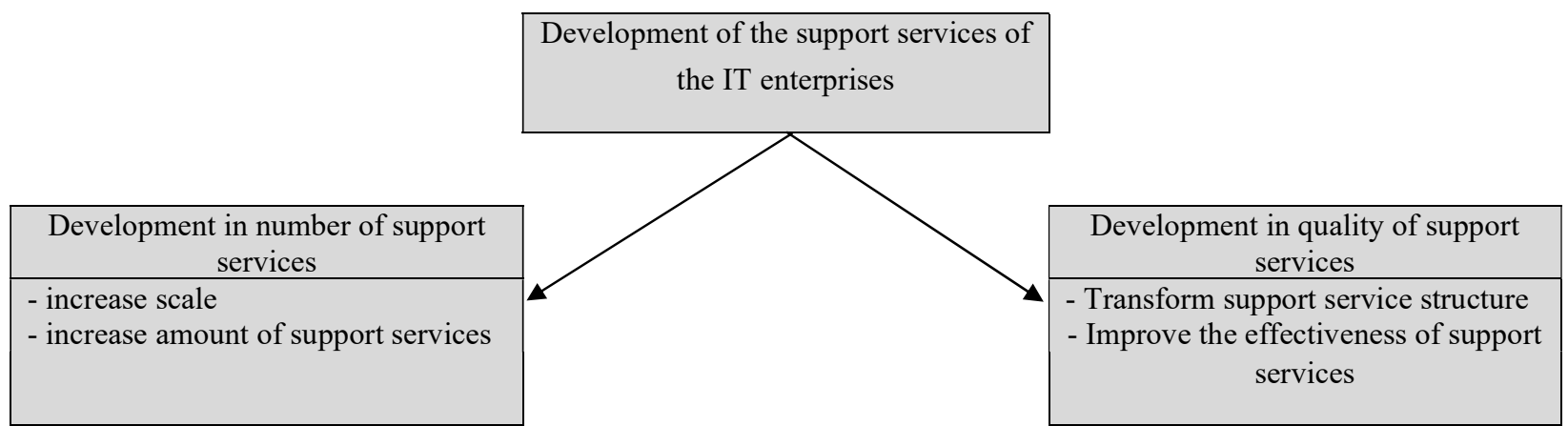

Fig. 3. Development of information technology support services

(Source: compiled by authors)

We can see that "Developing services to support information technology enterprises" is the process of making the scale grow, improving the quality and efficiency of services and perfecting the service structure to support well according to the needs of information technology enterprises. It is the process of self-mobilization of the system of support services according to the signals of the market and the orientation and impact of the State in order to create an environment for development from planning, orientation, tissue selection supply patterns, mechanisms, policies and operating conditions. In the study of factors affecting the development of IT support services in Vietnam, the paper uses qualitative research methods based on analysis of secondary data to assess negative effects positively to the development of supporting services industry in general. In order to clarify the probability of choosing to use information technology enterprises to each support service group, the article uses quantitative research methods to analyze the survey results of the use of support services. There are 315 information technology enterprises with 6 service groups including consulting services, promotion services, training services, technology services, connection services and intensive services. Applying the general studies combined with the diamond model of Porter (1998) 
and the comprehensive diagnostic model of Cummings and Cummings (2008), the authors propose a quantitative model of research saving probability of using IT support service in Vietnam context.

\subsection{Research hypothesis}

In the quantitative research model, to determine whether the factor has a positive or negative effect on the probability of using support services of information technology enterprises, the authors build a hypothesis to determine the linear relationship between this probability and the above 7 factors as stated in Fig. 4 and Table 5.

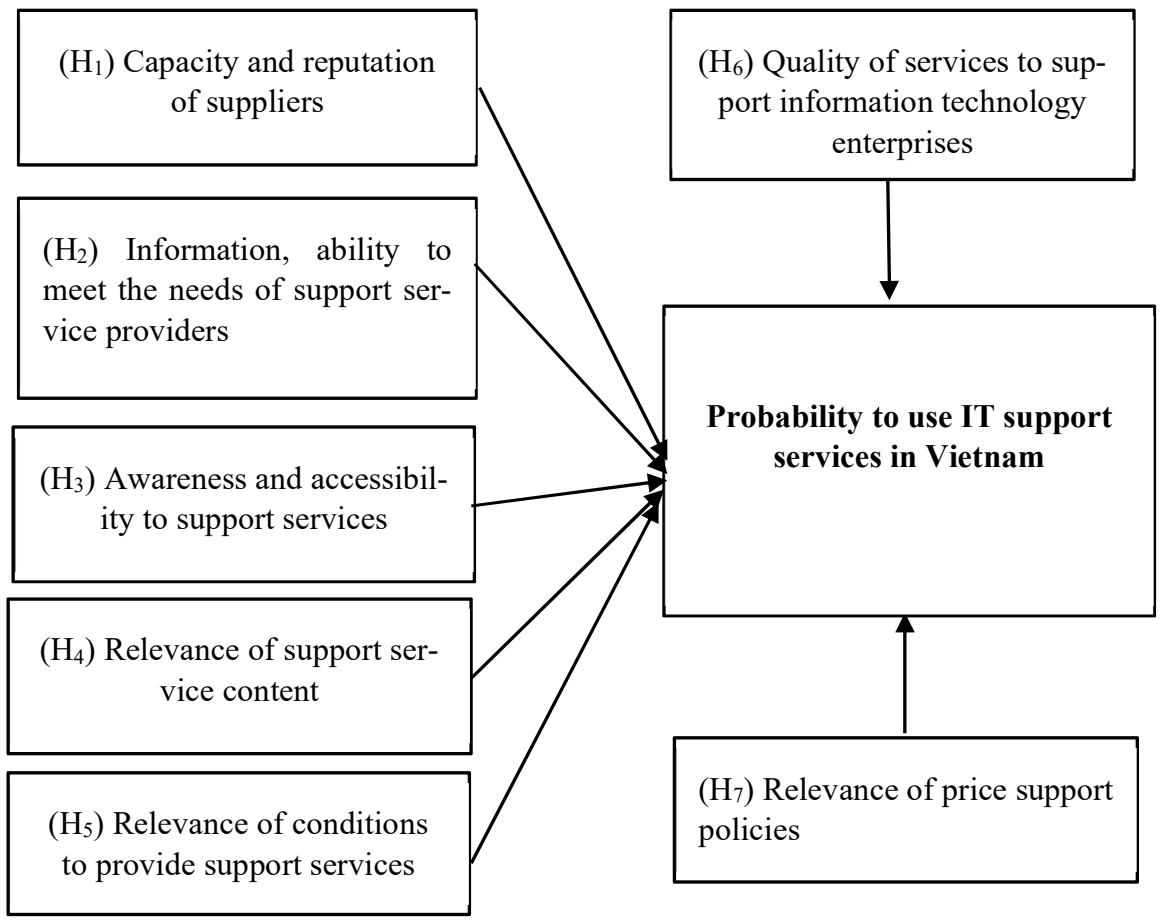

Fig. 4. Quantitative research model

(Source: compiled by authors)

Table 5

The hypothesis of the survey

\begin{tabular}{|c|c|}
\hline Hypothesis & Content \\
\hline H1 & $\begin{array}{l}\text { Relative positive between the capacity and prestige of suppliers with the probability of using information technology support services in } \\
\text { Vietnam }\end{array}$ \\
\hline $\mathrm{H} 2$ & $\begin{array}{l}\text { There is a positive relationship between information and ability to meet support needs of home services provide with the probability of using } \\
\text { information technology support services in Vietnam }\end{array}$ \\
\hline $\mathrm{H} 3$ & Yes Positive relationship between awareness and access to support services with the probability of using IT support services in Vietnam \\
\hline $\mathrm{H} 4$ & $\begin{array}{l}\text { There is a positive relationship between the relevance of the content of support services with the probability of using IT support services in } \\
\text { Vietnam }\end{array}$ \\
\hline H5 & $\begin{array}{l}\text { There is a positive relationship between the suitability of conditions of providing support services and the probability of using technology } \\
\text { support services information in Vietnam }\end{array}$ \\
\hline H6 & $\begin{array}{l}\text { There is a positive relationship between the quality of services to support IT enterprises with the probability of using information technology } \\
\text { support services in Vietnam }\end{array}$ \\
\hline H7 & $\begin{array}{l}\text { There is a positive relationship between the level of compliance combination of price support policy services with the probability of choosing } \\
\text { a business support service p information technology in Vietnam }\end{array}$ \\
\hline
\end{tabular}

\section{The results and analysis}

(Source: compiled by authors)

\section{Table 6}

Rate of selection of information technology services of surveyed enterprises

\begin{tabular}{lccccc}
\hline $\begin{array}{c}\text { Types of support } \\
\text { services }\end{array}$ & $\begin{array}{c}\text { Number of } \\
\text { enterprises Selecting }\end{array}$ & $\begin{array}{c}\text { Percentage } \\
(\%)\end{array}$ & $\begin{array}{c}\text { Number of enterprises Not } \\
\text { selected }\end{array}$ & $\begin{array}{c}\text { Percentage } \\
(\%)\end{array}$ & $\begin{array}{c}\text { Total } \\
\text { Advice }\end{array}$ \\
Promotion & 196 & 62.22 & 119 & 37.78 & 315 \\
Training & 88 & 27.94 & 227 & 72.06 & 315 \\
Technology & 22 & 6.98 & 293 & 93.02 & 315 \\
Connect & 33 & 10.48 & 282 & 89.52 & 315 \\
Intensive & 39 & 12.38 & 276 & 87.62 & 315 \\
Synthetic & 6 & 1.90 & 309 & 98.10 & 315 \\
& 221 & 70.16 & 94 & 29.84 & 315 \\
\hline
\end{tabular}


We have used SPSS 20.0 software and followed estimation method Backward (Ward). This is a method of gradually eliminating variables based on the probability of Wald statistics. The estimated results of the model are finalized in Table 7.

Comment: Quantitative research has carried out 7 models corresponding to 6 service areas and an overall model. However, through estimation, the Ycs model has not given desirable results. Verification of the models in the final estimation step shows that the models are suitable (Log Likelihood test), zero estimation coefficients (Chi-square) and values of Sig. $<0.05$. Information on the correct forecasting ratio also shows that the forecasted rate of all models is high, from $80 \%$ or more. This shows that the estimation models can be used for analysis and forecasting purposes. From the above results, it is possible to write a probabilistic regression model, calculate OR, ROR and evaluate the influence of factors on the probability of using corresponding support services. The following will be specific to the Consulting Service, while for other services as well as the general model, it will be calculated similarly and only summarize the results.

For consulting service model:

$$
P_{i}=\frac{e^{-2,445-0,717 X 2+0,657 X 3+1,099 X 4+0,71 X 5-0,664 X 6}}{1+e^{-2,445-0,717 X 2+0,657 X 3+1,099 X 4+0,71 X 5-0,664 X 6}}
$$

Table 7

Model estimation results

\begin{tabular}{|c|c|c|c|c|c|c|c|}
\hline $\begin{array}{c}\text { Variable } \\
\text { dependent }\end{array}$ & Independent variable & $\mathrm{B}$ & SE & Wald & $\mathrm{df}$ & Sig. & $\operatorname{Exp}(B)$ \\
\hline \multirow{6}{*}{$\begin{array}{l}\text { Step 3a } \\
\text { Ytv }\end{array}$} & $\mathrm{X}_{2}$ & -.717 & .340 & 4.455 & 1 & .035 & .488 \\
\hline & $\mathrm{X}_{3}$ & .657 & .337 & 3.788 & 1 & $.052 * *$ & 1.928 \\
\hline & $\mathrm{X}_{4}$ & 1.099 & .366 & 9.012 & 1 & .003 & 3.000 \\
\hline & $\mathrm{X}_{5}$ & .710 & .252 & 7.942 & 1 & .005 & 2.033 \\
\hline & $\mathrm{X}_{6}$ & -.664 & 664.320 & 4.301 & 1 & .038 & .515 \\
\hline & Constant & -2.445 & .380 & 41.443 & 1 & .000 & 000.087 \\
\hline \multirow{6}{*}{$\begin{array}{l}\text { Step 3a } \\
\text { Yxt }\end{array}$} & $\mathrm{X}_{1}$ & 1.036 & .242 & 18.321 & 1 & 000 & 2.817 \\
\hline & $\mathrm{X}_{4}$ & 1.197 & .308 & 15.124 & 1 & 000 & 3.309 \\
\hline & $\mathrm{X}_{5}$ & -.402 & .198 & 4.126 & 1 & .042 & .669 \\
\hline & $\mathrm{X}_{6}$ & -.680 & .237 & 8.243 & 1 & .004 & .506 \\
\hline & $\mathrm{X}_{7}$ & -.625 & .264 & 5.580 & 1 & .018 & .535 \\
\hline & Constant & -3.049 & .480 & 40.279 & 1 & .000 & .047 \\
\hline \multirow{3}{*}{$\begin{array}{l}\text { Step 6a } \\
\text { Ydt }\end{array}$} & $\mathrm{X}_{4}$ & 1.230 & .277 & 19.730 & 1 & .004 & .310 \\
\hline & $\mathrm{X}_{7}$ & -1.170 & .402 & 8.456 & 1 & .000 & .310 \\
\hline & Constant & -4.286 & .848 & 25.530 & 1 & .000 & .014 \\
\hline \multirow{6}{*}{$\begin{array}{l}\text { Step } \\
\text { Ycn }\end{array}$} & $\mathrm{X}_{1}$ & .663 & .336 & 3.894 & 1 & .048 & 1.940 \\
\hline & $\mathrm{X}_{2}$ & -.577 & .329 & 3.068 & 1 & $.080 * *$ & .562 \\
\hline & $\mathrm{X}_{4}$ & 1.758 & .425 & 17.096 & 1 & .000 & 5.798 \\
\hline & $\mathrm{X}_{5}$ & -.511 & .228 & 5.008 & 1 & .000 & .600 \\
\hline & $\mathrm{X}_{7}$ & -.846 & .356 & 5.647 & 1 & .017 & .429 \\
\hline & Constant & -4.793 & 1.029 & 21.706 & 1 & .000 & .008 \\
\hline Step 7a & $\mathrm{X}_{3}$. & 844 & .203 & 17.366 & 1 & .000 & 2.327 \\
\hline Ykn & Constant & -4.789 & .794 & 36.427 & 1 & .000 & .008 \\
\hline \multirow{6}{*}{$\begin{array}{c}\text { Step 3a } \\
Y\end{array}$} & $\mathrm{X}_{1}$ & 1.716 & .642 & 7.138 & 1 & .008 & 5.561 \\
\hline & $\mathrm{X}_{2}$ & -2.728 & .835 & 10.684 & 1 & .001 & .065 \\
\hline & $\mathrm{X}_{3}$ & 1.073 & .536 & 4.006 & 1 & .045 & 2.923 \\
\hline & $\mathrm{X}_{4}$ & 1.836 & .589 & 9.733 & 1 & .002 & 6.274 \\
\hline & $\mathrm{X}_{7}$ & -.864 & .509 & 2.886 & 1 & $.089^{* *}$ & .421 \\
\hline & Constant & -1.968 & .320 & 37.851 & 1 & .000 & .140 \\
\hline
\end{tabular}

**: Significant with $10 \%$ significance.

(Source: compiled by authors)

Among the variables that affect the dependent variable is $\mathrm{X}_{3}$ (Awareness and accessibility to support services of information technology enterprises) and $\mathrm{X}_{5}$ (Relevance of conditions to provide support services with business desire) are statistically significant at $10 \%$, while the remaining variables are significant at $5 \%$ level. The variables $\mathrm{X}_{3}, \mathrm{X}_{4}$ and $\mathrm{X}_{5}$ have coefficients of estimation of the step and the remaining variables $X_{2}$ and $X_{6}$ have negative coefficients. The independent variables from $X_{1}$ to $X_{7}$ are variables that show the level of judgment and assessment of service users. There are similarities when assessing the group of factors so the author chooses the evaluation levels to Probability (probability) enterprises with $\mathrm{X}=\mathrm{vectors}\left(\mathrm{X}_{1}, \mathrm{X}_{2}\right.$, $\mathrm{X}_{3}, \mathrm{X}_{4}, \mathrm{X}_{5}, \mathrm{X}_{6}, \mathrm{X}_{7}$ ). Based on the results on the article, the following criteria and ratios have been calculated:

Table 8

Probability level at vector X0

\begin{tabular}{lcrrrrrr}
\multicolumn{1}{c}{ Target } & Independence & $\mathbf{X = 0}$ & $\mathbf{X = 1}$ & $\mathbf{X = 2}$ & $\mathbf{X = 3}$ & $\mathbf{X}=\mathbf{4}$ & $\mathbf{X}=\mathbf{5}$ \\
\hline Ability Yxt $(=1)$ & $\hat{p}_{i}$ & 0.0798 & 0.2042 & 0.4317 & 0.6921 & 0.8693 & 0.9517 \\
Inability Yxt $(=0)$ & $1-\hat{p}_{i}$ & 0.9202 & 0.7958 & 0.5683 & 0.3079 & 0.1307 & 0.0483 \\
ratio OR & $\hat{p}_{i} / 1-\hat{p}_{i}$ & 0.0867 & 0.2566 & 0.7596 & 2.2479 & 6.6525 & 19.6878 \\
\hline
\end{tabular}

(Source: compiled by authors)

At level $\mathrm{X}=0$, when the enterprise does not evaluate the influencing factor groups, the possibility of enterprises still using the service is $7.98 \%$. When the satisfaction level increases gradually from 1 to 5 , the probability of enterprises choosing services also increases gradually, reaching $86.93 \%$ at the satisfaction level and nearly $95.17 \%$ when very satisfied. 


\section{OR ratio}

Corresponding to the rating levels $0,1,2$, the OR ratio is less than 1 , meaning the ability of the enterprise to use support services is smaller than the possibility of not using the corresponding support service is $8.67 \%, 25.66 \%$ and $75.96 \%$. But from level 3 onwards, this OR ratio is higher than 1 and increases very fast, indicating the possibility of businesses using support services greater than the ability to not use support services multiple times and highest in Very satisfied level is 19.68 times. With a rating of 3, the rate of businesses using support services is 2.25 times higher, this ratio is at 4.65 and at 5 is 19.68 times the enterprise does not use the service support.

\section{Effect of Xk variable to probability level}

According to Logit model, we calculate $\mathrm{P}(\mathrm{Y}=1)$ at the average of independent variables $\mathrm{X}=3$, we calculate the change of probability when an independent variable increases by 1 unit, other variables keep original.

\section{Table 9}

Effect of independent variables on the probability of using consulting services

\begin{tabular}{ccc}
\hline Independence variables & Increase (decrease) Probability & $\begin{array}{c}\text { Increase (decrease) } \\
\text { Ratio ROR }\end{array}$ \\
\hline X2 & -0.1528 & -0.512 \\
X3 & 0.1400 & 0.928 \\
X4 & 0.2342 & 2 \\
X5 & 0.1513 & 1.033 \\
X6 & -0.1415 & -0.485 \\
\hline
\end{tabular}

Table 10

(Source: compiled by authors)

Impact of factors on the ability to use support services

\begin{tabular}{|c|c|c|c|}
\hline $\begin{array}{l}\text { Types of SUPPORT SER- } \\
\text { VICES }\end{array}$ & Independent variables & $\begin{array}{c}\text { Increase (decrease) } \\
\text { probability }\end{array}$ & $\begin{array}{c}\text { Increase (decrease) } \\
\text { ratio ROR }\end{array}$ \\
\hline \multirow{5}{*}{ Ytv } & $\mathrm{X} 2$ & -0.1528 & -0.512 \\
\hline & $\mathrm{X} 3$ & 0.1400 & 0.928 \\
\hline & $\mathrm{X} 4$ & 0.2342 & 2 \\
\hline & $\mathrm{X} 5$ & 0.1513 & 1.033 \\
\hline & $\mathrm{X} 6$ & -0.1415 & -0.485 \\
\hline \multirow{5}{*}{ Yxt } & $\mathrm{X} 1$ & 0.1573 & 1.817 \\
\hline & $\mathrm{X} 4$ & 0.1818 & 2.309 \\
\hline & $\mathrm{X} 5$ & -0.0610 & -0.331 \\
\hline & $\mathrm{X} 6$ & -0.1033 & -0.494 \\
\hline & $\mathrm{X} 7$ & -0.0949 & -0.465 \\
\hline \multirow[t]{2}{*}{$\mathrm{Ydt}$} & $\mathrm{X} 4$ & 0.0196 & 2.421 \\
\hline & $\mathrm{X} 7$ & -0.0187 & -0.69 \\
\hline \multirow{5}{*}{ Ycn } & $\mathrm{X} 1$ & 0.0221 & 0.940 \\
\hline & $\mathrm{X} 2$ & -0.0192 & -0.438 \\
\hline & $\mathrm{X} 4$ & 0.0585 & 4.798 \\
\hline & X5 & -0.0170 & -0.400 \\
\hline & $\mathrm{X} 7$ & -0.0282 & -0.571 \\
\hline $\mathrm{Ykn}$ & $\mathrm{X} 3$ & 0.0724 & 1.327 \\
\hline \multirow{5}{*}{$\begin{array}{c}\text { General Services } \\
\mathrm{Y}\end{array}$} & $\mathrm{X} 1$ & 0.3165 & 4.561 \\
\hline & $\mathrm{X} 2$ & -0.5032 & -0.935 \\
\hline & $\mathrm{X} 3$ & 0.1979 & 1.923 \\
\hline & $\mathrm{X} 4$ & 0.3387 & 5.274 \\
\hline & $\mathrm{X} 7$ & -0.1594 & -0.579 \\
\hline
\end{tabular}

(Source: compiled by authors)

For Technology services: The variables $\mathrm{X}_{1}$ (Competence, reputation of suppliers), $\mathrm{X}_{4}$ (Content suitability with the needs of information technology enterprises) have positive effects, while $\mathrm{X}_{2}$ (Information, ability to meet business requirements), $\mathrm{X}_{5}$ (Relevance of conditions to provide support services) and $\mathrm{X}_{7}$ (Assessment of support price policy) have opposite trend. This indicates that IT businesses are more interested in the reputation and relevance of the content of support services than on terms of supply and price (Gronroos, 1978; Haveman, 1992).

For Connect service: There is only one variable, $\mathrm{X}_{3}$ (Awareness and accessibility of support services of information technology enterprises) with statistical significance and estimated coefficient with positive value. Therefore, increasing awareness and acceptability of information technology enterprises will have a great impact on the ability to use connection services. This also implies that IT businesses are currently lacking in connection with customers, researchers, and suppliers even with employees. The lack of professional business activities has led to a low efficiency and small market size is inevitable. 
For the synthesis of service types (General Service): There are 5 out of 7 variables with statistical significance, and up to 3 variables have positive effects. Thus, hypotheses $\mathrm{H}_{1}, \mathrm{H}_{3}$, and $\mathrm{H}_{4}$ are accepted, which means that there is a positive relationship between $\mathrm{X}_{1}$ (Supplier's capacity and reputation) and $\mathrm{X}_{3}$ (Awareness and accessibility to support services) and $\mathrm{X}_{4}(\mathrm{Content}$ suitability with the needs of information technology enterprises) with the probability of using information technology support services. The remaining hypotheses $\mathrm{H}_{2}, \mathrm{H}_{5}, \mathrm{H}_{6}$ and $\mathrm{H}_{7}$ are rejected, in which $\mathrm{X}_{7}$ (price policy) has the same opposite effect as in individual service types.

The Nagelkerke R-Square coefficient in step 3 is equal to 0.744 (Table 5, PL07), which demonstrates that the independent variables explain over $74.4 \%$ of the variation of the $\mathrm{Y}$ variable (Overall model). The rest is the effect of other variables. The overall service model with such an explanation level is quite good.

Thus, the most concern of businesses now is associated with the reputation of the suppliers, the relevance of the required content and awareness and the ability of enterprises to receive. When these factors are improved, they will strongly affect the ability of information technology enterprises to use support services.

\section{Conclusion}

From the quantitative research results, the effects of factors on the ability of using information technology support services by Logit model on survey data from 315 information technology enterprises have been investigated. The following conclusions can be drawn:

First, the rate of using support services was very low, the level of service use was not even, there were even big differences between different types of services. The consulting service was the type of service with the highest utilization rate with $62 \%$, the trade promotion service was only approximately equal to $28 \%$ and the effects of other variables were low. Especially the training service was only $7 \%$ and the service was less than $2 \%$. Thus, it can be said that almost information technology enterprises were not interested in support services. Increasing communication, dissemination and connection of information is essential in the future.

The capacity and prestige of the supplier $\left(\mathrm{X}_{1}\right.$ variable) was influential in most services as well as general services and the coefficient always had a positive sign (positive direction), and the results show that when credibility was raised to a point, the probability of general use could increase quite high (31.65\%). This shows that, in order to improve service utilization rates, suppliers need to improve their capacities and reputation in service provision.

The $\mathrm{X}_{3}$ variable (Awareness and accessibility to support services of information technology enterprises) was statistically significant in the consulting service model, connecting and synthesizing always had a positive coefficient and high influence level. The finding shows that information technology awareness and accessibility factors of information technology enterprises had a positive impact on the ability to use the service. This also indicates that IT companies have not been aware of the importance of support services over time, possibly due to awareness and because the scale of operations is too small. In the coming time, the propaganda and dissemination for enterprises to change their awareness is necessary and at the same time there should be a policy mechanism to create conditions for enterprises to increase their scale and expand the scope of business activities.

The effect of variable $\mathrm{X}_{4}$ (Content suitability with the needs of information technology enterprises) was meaningful in 5 out of 6 service models and the coefficient yielded positive value which is a good sign that the model has shown out. The impact of this factor is also quite large, from $18 \%$ to $33 \%$ when improving the perception of information technology enterprises to one unit. This is to say that currently, the content of support services is not really suitable for the content that information technology enterprises require, should be improved in the future.

The effect of $\mathrm{X}_{2}$ (Information and ability to meet provider support needs) with negative signs means the opposite effect. This shows that information technology enterprises do not appreciate the ability to meet the needs of support service providers.

The effect of $\mathrm{X}_{5}$ (Service suitability level) is significant in the consulting service model - the type of service chosen by businesses most recently. That is, satisfaction with service quality, price, and smooth information always has a positive impact on the desire to use support services. If there is an improvement in these aspects, the choice of IT services consulting services will increase rapidly.

The effect of $\mathrm{X}_{6}$ (Comments on service quality) is only statistically significant for two models of Consultancy and Trade Promotion services, but the coefficients are negative and this is inconsistent with reality. However, if we observe the evaluation points through the survey, the average value of the $\mathrm{X}_{6}$ is only 2.59 - i.e. below the "No opinion" level. That is, almost no information technology enterprises are aware of what the service quality is. The reason may be, on the one hand, information technology enterprises have not been used much, so they do not have an assessment, or the quality of services is not clear, etc. Therefore, it is necessary to overcome this situation from both suppliers and businesses.

The effect of $\mathrm{X}_{7}$ (Comments on service price policy) was statistically significant in 3 out of 6 models, including the general service model, however, the coefficient was negative. As mentioned above, the current price policy is not meaningful, most businesses only use the free types of services primarily, so in fact, market relations in provision of business support services in Vietnam is still in its primitive form. Services of a market nature such as training services have high prices, which lead to 
the situation that many IT enterprises organize their own training at home with lecturers who are mostly leader's work in the business. Therefore, the solution to develop the information technology service market in the coming time is very important.

\section{Acknowledgment}

This research is funded by National Economics University, Hanoi, Vietnam. The authors also would like to thank the anonymous referees for constructive comments on earlier version of this paper.

\section{References}

Armenakis, A. A., \& Bedeian, A. G. (1999). Organizational change: A review of theory and research in the 1990s. Journal of management, 25(3), 293-315.

Bell, J. (1997). A comparative study of the export problems of small computer software exporters in Finland, Ireland and Norway. International Business Review, 6(6), 585-604.

Berry, A. J., Sweeting, R., \& Goto, J. (2006). The effect of business advisers on the performance of SMEs. Journal of Small Business and Enterprise Development, 13(1), 33-47.

Boter, H., \& Lundström, A. (2005). SME perspectives on business support services: The role of company size, industry and location. Journal of small business and enterprise development, 12(2), 244-258.

Brijlal, P. (2008). Business development service: Addressing the gap in the western cape, South Africa. International Business \& Economics Research Journal, 7(9), 16-30.

Cummings, T. G., \& Cummings, T. G. (2008). Theory of organization development and change. South-Western Publications.

Edgecomb, E., \& Thetford, T. (2010). Focused Growth on Scaling Business Development Services in the United States. Findings Report from Field. Aspen Institute, USA. ISBN: 0-89843-523-5.

Edgcomb, E., \& Thetford, T. (2012). Benchmarking the Performance of Business Development Services. The Aspen Institute/FIELD, 50-69.

Eiligmann, A. (2005). Making business development services markets work for the poor. GTZ, Eschborn.

El Wassal, K. A. (2013). The development of stock markets: In search of a theory. International Journal of Economics and Financial Issues, 3(3), 606-624.

Ensign, P. C. (2001). Value chain analysis and competitive advantage. Journal of General Management, 27(1), 18-42.

Govindaraju, R., \& Lukman, K. (2012). The development of model on operational capabilities of IT vendor serving offshore services: case study in an Indonesian IT company. Procedia-Social and Behavioral Sciences, 65, 443-448.

Gronroos, C. (1978). A service-orientated approach to marketing of services. European Journal of marketing, 12 (8), $588-601$.

Haveman, H.A. (1992). Between a rock and a hard place: Organisational change and failure under conditions of fundamental environmental transformation. Adminisfrative Science Quarterly, 37, 48- 54.

Kim, C., Oh, E., \& Shin, N. (2010). An empirical investigation of digital content characteristics, value, and flow. Journal of Computer Information Systems, 50(4), 79-87.

Kox, H., Van Leeuwen, G., \& Van der Wiel, H. (2007). Market structure, productivity and scale in European business services. In Business Services in European Economic Growth(pp. 195-212). Palgrave Macmillan, London.

Miehlbradt, A. (2002). Assessing Markets for Business Development Services: What have we learned so far?. Small Enterprise Development, 13(3), 54-66.

Miehlbradt, A. O., \& McVay, M. (2003). Developing commercial markets for business development services. BDS primer. In 4th annual BDS seminar, Turin, September.

Mole, K. (2002). Street-level technocracy in UK small business support: Business Links, personal business advisers, and the Small Business Service. Environment and Planning C: Government and Policy, 20(2), 179-194.

Mole, K. F., Hart, M., Roper, S., \& Saal, D. S. (2009). Assessing the effectiveness of business support services in England: Evidence from a theory-based evaluation. International Small Business Journal, 27(5), 557-582.

Porter, M. E. (1998). Clusters and the new economics of competition (Vol. 76, No. 6, pp. 77-90). Boston: Harvard Business Review.

Romijn, H. A., Caniëls, M. C. J., \& de Ruijter-de Wildt, M. (2003, June). Can business development services practitioners learn from theories on innovation and services marketing?. In European Network for Industrial Policy (EUNIP) Conference, Porto, 18-22 September 2003. EUNIP.

Roper, S., \& Hart, M. (2005). Small firm growth and public policy in the UK: what exactly are the connections?. Aston University Business School.

Sheikh, S., Pecher, I., Steiber, N., \& Heckl, E. (2002). Support services for micro, small and sole proprietor's businesses. European Commission, Enterprise Directorate-General.

Wren, C., \& Storey, D. J. (2002). Evaluating the effect of soft business support upon small firm performance. Oxford Economic Papers, 54(2), 334-365. 
(C) 2020 by the authors; licensee Growing Science, Canada. This is an open access article distributed under the terms and conditions of the Creative Commons Attribution (CCBY) license (http://creativecommons.org/licenses/by/4.0/). 